\title{
R\&D intensity and its influence on renewable energy consumption: Evidence from selected Asian economies
}

Wei Li

Zhejiang Gongshang University

Sana Ullah ( $\nabla$ sana_ullah133@yahoo.com )

Quaid-i-Azam University https://orcid.org/0000-0003-3431-9776

\section{Research Article}

Keywords: R\&D intensity, Renewable energy consumption

Posted Date: January 17th, 2022

DOI: https://doi.org/10.21203/rs.3.rs-1161152/v1

License: () (7) This work is licensed under a Creative Commons Attribution 4.0 International License. Read Full License 


\section{Abstract}

The main objective of this study is to investigate the impact of research and development (R\&D) intensity on renewable energy consumption in Asian economies. We have relied on the autoregressive distributive lag (ARDL) model to get empirical estimates. The results show that the short and long-run estimates attached to R\&D intensity are significantly positive in China and Japan, signifying that a rise in R\&D intensity increases the renewable energy consumption in China and Japan. Conversely, the short-run estimated coefficients of energy intensity are significantly negative in India and positive in Japan. In the long run, the estimates of energy intensity are positive and significant in India and Japan only. Among the control variables, the rise in CO2 emissions causes renewable energy consumption to rise in all three economies in the long run. However, the long-run effects of an increase in trade also positively affect renewable energy consumption in China and Japan. Lastly, a rise in financial development gives rise to renewable energy consumption in the long run in China only. On the policy front, policymakers should promote investment in R\&D to minimize the costs of conventional energy consumption.

\section{Introduction}

Over the last few decades, the world has observed massive greenhouse gases emissions due to anthropogenic activities. The infusion of greenhouse gases emissions into the atmosphere is one of the most significant causes of global warming and climate change which have become the focus of discussion at international forums. As a result, the focus of empirical researchers in environmental and energy economics has shifted to analyze the factors that can significantly control greenhouse gases emissions, particularly carbon emissions. In this regard, a plethora of studies is available that have examined various determinants of environmental quality, such as renewable energy, GDP, trade, globalization, urbanization, ICT, and tourism, among others (see, Dinda, 2004, Ullah et al. 2021; Usman et al. 2021). Most of the studies have included various determinants in the framework of the Environmental Kuznets Curve (EKC), which says that there exists an inverted U-shaped association between economic growth and $\mathrm{CO} 2$ emissions. In other words, EKC suggests that environmental quality deteriorates during the early stages of development and improves once the growth process is consolidated. Nevertheless, a consensus has emerged among the researchers that have tested the EKC hypothesis that technological improvement is one of the significant determinants of better environmental quality. Such an improvement in the environment via technological advancement is given the name of "technological effects".

According to endogenous growth theory, investment in research and development can lead to the promotion of technological advancement that will eventually increase the level of production efficiency and encourage the efficient use of natural resources and energy. As the level of economic prosperity increases, the country can make more expenditure on research and development activities, resulting in the development of more sophisticated and advanced technology. Such sophisticated and advanced technologies can lead to the more efficient use of natural resources and produce less waste and emissions (Dinda, 2004), resulting in a better, pure, and green environment (Komen et al., 1997). For example, spending more on research and development projects improves environmental quality by effectively managing the waste management system to guarantee fewer waste discharges (Arora and Cason, 1996).

However, the relationship between carbon emissions and technology is not clear. On one side, research and development can positively impact growth and trade via scale effect (Castellani and Pieri, 2013; Minniti and Venturini, 2017).On the other hand, increased production and trade activities can negatively impact environmental quality. Although newer and modern technology can bring more efficiency in the production process; however, increasing output still needs to utilize more natural resources and input that deteriorate environmental quality by releasing more CO2 emissions (Jian et al., 2021). The law of diminishing returns is also applicable to the process of research and development. Over time as the accumulation of knowledge increases, the development of newer technology requires much more time, effort, and budget resulting in a reduced level of research and development activities (Newell et al., 2009). Nonetheless, the process of economic growth demands more inputs and natural resources.

Although we can draw some inferences from the EKC model's technological effect, in-depth knowledge on the association between research and development and $\mathrm{CO} 2$ emissions across countries is still missing. One school of thought has used models like Integrated Assessment Models (Bosetti and Tavoni, 2009; Grimaud et al., 2011; Marangoni and Tavoni, 2014) to analyze the relationship between research and development intensity and environmental quality. Overall, the findings of these studies confirmed the positive link between research and development and $\mathrm{CO} 2$ emissions; however, research and development expenditures alone are not enough, and a lot will depend on the improved performance of contemporary technologies.

The second group of studies includes those studies that have examined the said relationship in the context of firms, countries, and regions by using panel data over the period of 10-20 years. For instance, in the context of Japanese firms for 2001-2010, Lee and Min (2015) analyzed the relationship between green research and development and $\mathrm{CO} 2$ emissions. Zhou et al. (2017) analyzed the relationship between research and development and $\mathrm{CO} 2$ emissions for Chinese provinces. For 13 advanced economies, Garrone and Grilli (2010) observed the relationship between research and development in energy and CO2 emissions over the period 1980-2004. For 13 advanced economies, Garrone and Grilli (2010) analyzed the link between research and development in energy and $\mathrm{CO} 2$ productions for the period 1980-2004. Fernandez et al. (2018) analyzed the impact of research and development activities on environmental quality in three different economies, including China, the European Union (EU), and the United States (US) for the period 1990-2013. Li and Wang (2017) examined the impact of technological change on $\mathrm{CO} 2$ emissions by gathering data for 95 countries.

$R \& D$ is connected with renewable energy consumption through various channels. For instance, R\&D can moderate renewable energy consumption by triggering technological innovation in the energy sector (Yao et al., 2019). Endogenous growth theory reveals that technological innovation and progress from investing in the R\&D sector could enhance the effectiveness of energy production and consumption. Hence, R\&D intensity results in reducing over-dependence on natural resources by empowering more effective technologies that alleviate production-based CO2 emissions (Churchill et al., 2021; Dinda, 2004). Moreover, through an increase in economic development and provision of more opportunities for trade openness, R\&D intensity results in high use of energy due to increased production associated with economic development and trade openness. It happens when nations experience diminishing margining returns to R\&D and innovation over time. It states that due to an increase in knowledge accumulation, the innovations become more challenging, hence resulting in reducing 
R\&D-specific returns (Newell, 2009). The impact of R\&D intensity on energy consumption becomes more aggravated when consumption of energy is separated into dirty and clean energy components.

On 4 November 2016, an important agreement regarding climate change, the Paris Agreement, came into effect. This agreement demands the member states reduce carbon emissions significantly. They agreed that increasing the role of renewable energy is the most viable solution to achieve the said target. It is widely recognized that increasing the installed capacity of renewable energy is an efficient technique in the long-term transformation of the global energy system. Moreover, three international organizations such as Renewable Energy Policy Network for the 21st Century (REN 21), International Energy Agency (IEA), and United Nations Environmental Programme (UNEP), also pointed out that without increasing the share of renewable energy in the total energy mix the goal of sustainable environment can't be realized. To that end, most economies are replacing their energy structure loaded with fossil fuels energy with the energy structure based on renewable energy sources that will eventually lead to the complete transformation of the energy system. The increased investment in research and development expenditures can help replace non-renewable energies with renewable energies in the nations' energy structure, resulting in a cleaner environment. Very few studies in the literature are available that have analyzed the impact of research and development intensity on renewable energy consumption in Asian economies.

\section{Model And Methods}

Following earlier empirical and theoretical literature of Wang et al. (2020) and Churchill et al. (2021), we assume that the main determinants of the renewable energy consumption model are R\&D intensity, energy intensity, environmental pressures, trade, and financial development. Therefore, we begin with the following econometric model:

$$
\mathrm{REC}_{\mathrm{t}}=\phi_{0}+\phi_{1} \mathrm{RD}_{\mathrm{t}}+\phi_{2} \mathrm{EI}_{\mathrm{t}}+\phi_{3} \mathrm{CO}_{2, \mathrm{t}}+\phi_{4} \operatorname{Trade}_{\mathrm{t}}+\phi_{5} \mathrm{FD}_{\mathrm{t}}+\epsilon_{\mathrm{t}}(1)
$$

Where REC is the renewable energy consumption that depends on R\&D intensity (RD), energy intensity (EI), CO2 emissions (CO2), trade openness (Trade), and financial development (FD). Since an increase in R\&D intensity is expected to increase renewable energy consumption, we expect an estimate of $\phi_{1}$ to be positive. Energy intensity can improve renewable energy consumption by reducing the harms of dirty energy consumption, thus we expect an estimate of $\phi_{1}$ to be positive. Also, since an increase in environmental pressures is expected to boost consumption of renewable energy, we expect an estimate of $\phi_{3}$ to be positive. Finally, trade and financial development boost and open new sources of clean energy thus estimate of $\phi_{4} \& \phi_{5}$ are expected to be positive. The coefficient estimates reported above in equation (1) are long-run estimates. Since specification (1) is a long-run model, it cannot be used to scrutinize short-run effects. In order to assess short-run effects, specification (1) must be expressed in an error-correction format as follows:

$\Delta \mathrm{REC}_{\mathrm{t}}=\phi_{0}+\sum_{\mathrm{k}=1}^{\mathrm{n}} \beta_{1 \mathrm{k}} \Delta \mathrm{REC}_{\mathrm{t}-\mathrm{k}}+\sum_{\mathrm{k}=0}^{\mathrm{n}} \beta_{2 \mathrm{k}} \Delta \mathrm{RD}_{\mathrm{t}-\mathrm{k}}+\sum_{\mathrm{k}=1}^{\mathrm{n}} \beta_{3 \mathrm{k}} \Delta \mathrm{EI} \mathrm{I}_{\mathrm{t}-\mathrm{k}}+\sum_{\mathrm{k}=0}^{\mathrm{n}} \beta_{4 \mathrm{k}} \Delta \mathrm{CO}_{2, \mathrm{t}-\mathrm{k}}+\sum_{\mathrm{k}=1}^{\mathrm{n}} \beta_{5 \mathrm{k}} \Delta \operatorname{Trade}_{\mathrm{t}-\mathrm{k}}+\sum_{\mathrm{k}=0}^{\mathrm{n}} \beta_{6 \mathrm{k}} \Delta \mathrm{FD}_{\mathrm{t}-\mathrm{k}}$

Specification (2) is an error-correction model where coefficient estimates attached to " $\Delta$ " variables reveal short-run effects and estimates of $\Pi_{2}-\Pi_{6}$ normalized on $\Pi_{1}$ produce long-run effects. A prior study of Pesaran et al. (2001) recommends two diagnostic tests (e.g., F-test and ECM or t-test) to establish cointegration so that we can avoid spurious time series estimates. The $\mathrm{F}$ test establishes the joint level of significance of lagged variables in specification (2) and the ECM or t-test to establish the significance of $\lambda$. The null hypothesis in the equation is H0: $\phi_{1}=\phi_{2}=\phi_{3}=\phi_{4}=\phi_{5}=\phi_{6}=0$. This infers the nonexistence of cointegration, but the alternative is $\mathrm{H} 1$ : $\phi_{1} \neq 0, \phi_{2} \neq 0, \phi_{3} \neq 0, \phi_{4} \neq 0, \phi_{5} \neq 0, \phi_{6} \neq 0$. The ARDL has numerous benefits to the other methods of cointegration. Another edge is that since almost all macro time series variables are either I(1) or I( 0$)$, so for there is not essential to engaging in pre-unit root testing. To confirm the stationarity of the time series we have relied on two unit root tests namely the Dickey Fuller-Generalized Least Square (DFGLS) and Phillips-Perron (PP). This approach can estimate short and long-run coefficients in a single step. This method takes a sufficient number of lags to capture the data generating process in a dynamic context of a general-to-specific modeling framework. Besides, endogeneity is less of a problem in ARDL method because it is problem-free of residual correlation. To confirm the goodness of fit of the econometric model, some diagnostics and stability tests are also used. Diagnostic tests are those of the first-order serial correlation (LM), misspecification (RESET), and parametric instability (CUSUM and CUSUM-sq) are also employed.

\section{Data}

$R \& D$ intensity impact on renewable energy consumption is examined for Asian economies for time-period 1990 to 2019 . Table 1 provides details regarding symbols, definitions, and sources of data. Data for renewable energy consumption is obtained from ElA which is measured in terms of nuclear, renewables and other in quad BTU. However, data for focused variable i.e. R\&D intensity is taken from the World Bank and it is calculated as R\&D expenditures in percent of GDP. Data for control variables, such as energy intensity, CO2 emissions, trade, and financial development, is sourced from the World Bank. Energy intensity is measured as the energy intensity level of primary energy while $\mathrm{CO} 2$ emission is taken into kilotons of carbon dioxide emission. Trade is measured in percent of GDP and financial development is measured in terms of domestic credit to private sector in percent of GDP. The descriptive statistics of the variables are given in Table 2. 
Table 1

Variables and sources

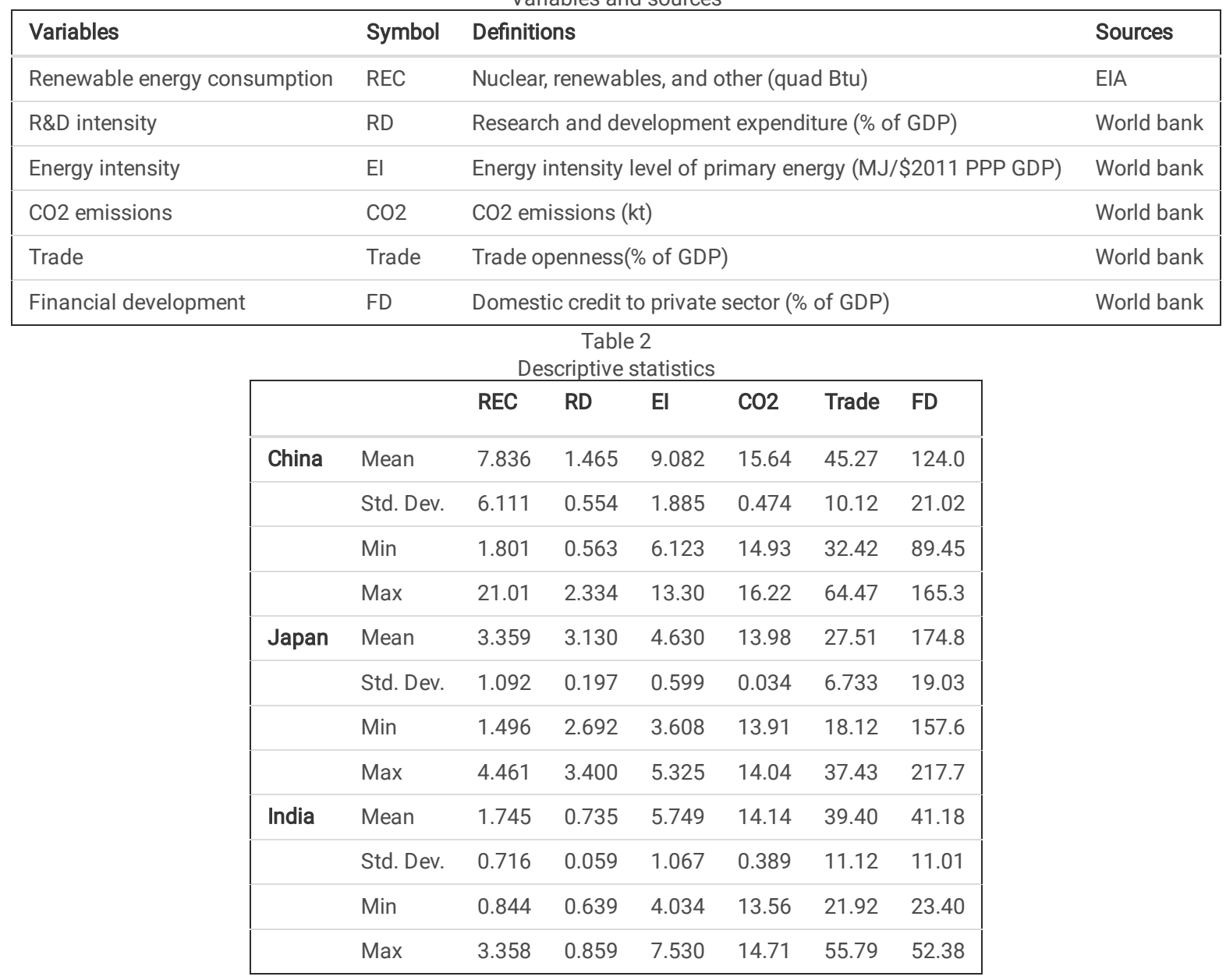

\section{Results And Discussion}

Before performing regression analysis, unit root characteristics of variables are tested by applying PP tests and DF-GLS test. Table 3 displays the empirical outcomes of PP test and DF-GLS test. We find that some variables are stationary at level i.e., I(0), while others confirm non-stationarity at the level. These variables become stationary after taking their first difference. In short, there is a mixture of order of integration i.e. I(0) and I( 1$)$ series of variables in the model. Findings of unit root tests encouraged us to use the ARDL approach for empirical investigation. Table 4 reports the short-run and long-run coefficient estimates of ARDL models for all three selected economies. In Table 4, Panel (a) displays short-run coefficient estimates of all three models, panel (b) represents long-run findings, and panel (c) provides findings of some necessary diagnostic tests. 
Table 3

Unit root testing

\begin{tabular}{|c|c|c|c|c|c|c|c|}
\hline & & PP & & & DF-GLS & & \\
\hline & & $\mathrm{I}(0)$ & $\mathrm{I}(1)$ & Decision & $\mathrm{I}(0)$ & $\mathrm{I}(1)$ & Decision \\
\hline \multirow[t]{6}{*}{ China } & REC & $-2.734^{\star}$ & & $\mathrm{I}(0)$ & $-1.986^{* *}$ & & $\mathrm{I}(0)$ \\
\hline & $\mathrm{RD}$ & -0.453 & $-4.243^{\star \star \star}$ & $\mathrm{I}(1)$ & 0.562 & $-4.325^{\star \star \star}$ & $\mathrm{I}(1)$ \\
\hline & $\mathrm{El}$ & -1.882 & $-3.101^{\star *}$ & $\mathrm{I}(1)$ & 0.875 & $-2.325^{\star \star}$ & $\mathrm{I}(1)$ \\
\hline & $\mathrm{CO} 2$ & -0.915 & $-2.631^{\star \star}$ & $\mathrm{I}(1)$ & -0.623 & -1.968 ** & $\mathrm{I}(1)$ \\
\hline & TRADE & $-3.012^{\star \star}$ & & $\mathrm{I}(0)$ & $-1.752^{\star}$ & & $\mathrm{I}(0)$ \\
\hline & FD & -0.356 & $-4.052^{\star * \star}$ & $\mathrm{I}(1)$ & -0.289 & $-3.259 * * *$ & $\mathrm{I}(1)$ \\
\hline \multirow[t]{6}{*}{ India } & REC & 0.184 & $-3.828^{* \star \star}$ & $\mathrm{I}(1)$ & 0.653 & $-3.875^{\star \star \star}$ & $\mathrm{I}(1)$ \\
\hline & $\mathrm{RD}$ & -1.912 & $-3.521^{\star \star}$ & $\mathrm{I}(1)$ & -1.564 & $-3.065^{\star \star \star}$ & $\mathrm{I}(1)$ \\
\hline & $\mathrm{El}$ & -0.475 & $-5.258^{\star \star \star}$ & $\mathrm{I}(1)$ & -0.145 & $-4.152^{\star \star \star}$ & $\mathrm{I}(1)$ \\
\hline & $\mathrm{CO} 2$ & -0.378 & $-4.094^{\star \star \star}$ & $\mathrm{I}(1)$ & -0.785 & $-4.123^{\star \star \star}$ & $\mathrm{I}(1)$ \\
\hline & TRADE & -1.634 & $-3.954^{\star \star \star}$ & $\mathrm{I}(1)$ & $-1.896^{*}$ & & $\mathrm{I}(0)$ \\
\hline & $\mathrm{FD}$ & $-2.634^{\star}$ & & $\mathrm{I}(0)$ & $-1.752^{\star}$ & & $\mathrm{I}(0)$ \\
\hline \multirow[t]{6}{*}{ Japan } & REC & -1.111 & $-3.435^{\star \star}$ & $\mathrm{I}(1)$ & -1.023 & $-3.895^{\star \star \star}$ & $\mathrm{I}(1)$ \\
\hline & $\mathrm{RD}$ & $-2.854^{\star \star}$ & & $\mathrm{I}(0)$ & $-2.185^{\star \star}$ & & $\mathrm{I}(0)$ \\
\hline & $\mathrm{El}$ & 0.886 & $-4.455^{\star \star \star}$ & $\mathrm{I}(1)$ & 0.621 & $-4.125^{\star \star \star}$ & $\mathrm{I}(1)$ \\
\hline & $\mathrm{CO} 2$ & 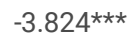 & & $\mathrm{I}(0)$ & $-3.545^{\star \star \star}$ & & $\mathrm{I}(0)$ \\
\hline & TRADE & -1.181 & $-4.993^{\star \star \star}$ & $\mathrm{I}(1)$ & -1.256 & $-4.356^{\star \star \star}$ & $\mathrm{I}(1)$ \\
\hline & FD & -1.326 & $-3.661^{\star \star}$ & $\mathrm{I}(1)$ & -1.356 & $-3.456^{\star \star \star}$ & $\mathrm{I}(1)$ \\
\hline Note: & 0.01; & $.05 ;$ * & & & & & \\
\hline
\end{tabular}

We find that R\&D intensity effect on renewable energy consumption is positive and statistically significant at the $10 \%$ level in China and $1 \%$ level in Japan in the long-run. We find that a 1 percent increase in R\&D intensity increases renewable energy consumption by 2.023 percent in China and 1.826 percent in Japan in the long-run. Our findings demonstrate that promoting R\&D could be an effective policy tool to increase renewable energy consumption in China and Japan. However, R\&D intensity has an insignificant impact on renewable energy consumption in India in the long-run.

This finding is also consistent with Churchill et al. (2021), who noted that increased investment in R\&D is promoting the consumption of renewable energy in OECD. It is considered that R\&D causes a substitution away from non-renewable energy consumption toward renewable energy consumption. This finding is also supported by Yao et al. (2019), who infer that R\&D reduces conventional energy consumption by improving clean energy consumption. This also means that R\&D investment promotes efficiency in the energy market by improving renewable energy consumption. The R\&D intensity induces slow expansion of renewable energy consumption, while the use of fossil fuels declines over a period. We also observed that R\&D intensity can also increase structural changes and promote diversity in the energy market. China has a relatively large share of R\&D, which in turn consumes more renewable energy consumption.

Environmental economist has more emphasized R\&D as one of the viable options to boost renewable energy consumption, and consequently reduce carbon emissions. R\&D investments tend to decrease the reliance on natural resources by permitting more efficient renewable energy consumption (Dinda, 2004). Normally R\&D may lead to higher renewable energy consumption as a result of increased renewable energy production. Studies done by Meleddu and Pulina (2018) claims that R\&D intensity contributes significantly to reducing the risk of new technologies, and their associated benefits to sustainability, security, and environmental protection.

Control variables report a positive and statistically significant positive impact on renewable energy consumption in most cases but with different magnitude. It is shown that energy intensity reports a positive and statistically significant impact on renewable energy consumption in case of China and India. We find that 1 percent upsurge in energy intensity increases renewable energy consumption by 0.183 percent in China and 0.330 percent in India. This infers that energy intensity reflects the efficiency of energy utilization, which can decrease the consumption of renewable energy. The association between CO2 emissions and the renewable energy consumption is positive and statistically significant in all three economies. We find that a 1 percent intensification of $\mathrm{CO} 2$ increases renewable energy consumption by 2.212 percent in China, 0.954 percent in India, and 1.334 percent in Japan in the long-run. Trade reports significant and positive impact on renewable energy consumption in India and Japan. It is found that 1 percent expansion in trade increases renewable energy consumption by 0.048 percent in India and 0.251 percent in Japan. Financial development reports a significant and positive impact on renewable energy consumption in China and India in the long-run. It is shown that 1 percent increase in financial development increases renewable energy consumption by 2.857 percent in China and 2.002 percent in India.

In the short-run, we find that the impact of research and development intensity on renewable energy consumption is positive and significant in China and Japan. The association between energy intensity and renewable energy consumption is negative and significant in India, while positive and significant in 
Japan. CO2 emissions report a significant and positive effect on renewable energy consumption in China and Japan. The linkage between trade and renewable energy consumption is positive and statistically significant in case of India only. However, the impact of financial development on renewable energy consumption is negative and statistically significant in case of India only in the short-run. In the lower panel of Table 4, findings of diagnostic tests reveal that long-run cointegration exists among variables in all three models as shown by statistically significant coefficient estimates of F-statistics and ECM. The negative sign attached with ECM confirms that short-run deviation converges towards equilibrium in the long-run. Findings of LM and BP tests denote that all their models are free from autocorrelation and heteroskedasticity issues. Error terms are also normally distributed and models are stable as shown by findings of Ramsey RESET test and CUSUM and CUSUM-sq tests.

Table 4

Short and long-run estimates of ARDL

\begin{tabular}{|c|c|c|c|c|c|c|}
\hline & China & & India & & Japan & \\
\hline Variable & Coefficient & t-Stat & Coefficient & t-Stat & Coefficient & t-Stat \\
\hline \multicolumn{7}{|l|}{ Short-run } \\
\hline $\mathrm{D}(\mathrm{RD})$ & $2.963^{\star \star}$ & 2.254 & 0.243 & 0.263 & $1.311^{\star \star \star}$ & 2.969 \\
\hline $\mathrm{D}(\mathrm{El})$ & 0.025 & 0.089 & $-0.542^{\star \star \star}$ & 4.073 & $3.079 \star \star \star$ & 4.835 \\
\hline $\mathrm{D}(\mathrm{EI}(-1))$ & & 0.325 & 0.545 & & 0.366 & 0.871 \\
\hline $\mathrm{D}(\mathrm{CO} 2)$ & $2.927 * \star$ & 2.145 & 0.389 & 0.705 & $2.363^{\star \star \star}$ & 3.921 \\
\hline $\mathrm{D}(\mathrm{CO} 2(-1))$ & 2.722 & 1.388 & & & & \\
\hline D(TRADE) & 0.015 & 0.610 & $0.020 * \star$ & 2.545 & -0.011 & 0.331 \\
\hline $\mathrm{D}(\operatorname{TRADE}(-1))$ & & & & & 0.038 & 1.207 \\
\hline $\mathrm{D}(\mathrm{FD})$ & -2.325 & 0.992 & $-2.039 * * *$ & 2.850 & -0.210 & 0.134 \\
\hline $\mathrm{D}(\mathrm{FD}(-1))$ & 2.648 & 1.476 & & & & \\
\hline \multicolumn{7}{|l|}{ Long-run } \\
\hline $\mathrm{RD}$ & $2.023^{\star}$ & 1.670 & 0.596 & 0.276 & 1.826 *** & 2.632 \\
\hline $\mathrm{El}$ & $0.183^{* *}$ & 2.091 & 0.330 ** & 2.285 & 0.574 & 0.781 \\
\hline $\mathrm{CO} 2$ & $2.212^{*}$ & 1.908 & $0.954^{*}$ & 1.922 & $1.334^{\star \star \star}$ & 3.225 \\
\hline TRADE & 0.112 & 0.745 & $0.048^{*}$ & 1.665 & $0.251^{*}$ & 1.946 \\
\hline FD & 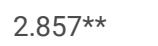 & 2.077 & $2.002^{\star \star}$ & 2.272 & 2.837 & 1.331 \\
\hline C & $8.306^{\star \star}$ & 2.032 & 12.10 & 0.579 & 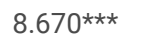 & 2.685 \\
\hline \multicolumn{7}{|l|}{ Diagnostics } \\
\hline F-test & $4.593^{*}$ & & $11.23^{\star \star \star}$ & & $4.123^{*}$ & \\
\hline $\operatorname{ECM}(-1)$ & $-0.334 *$ & 1.692 & $-0.408^{\star \star}$ & 2.011 & -0.527 & 4.756 \\
\hline \multicolumn{7}{|l|}{$\mathrm{R} 2$} \\
\hline LM & 1.245 & & 2.032 & & 1.356 & \\
\hline BP & 1.287 & & 1.742 & & 1.195 & \\
\hline RESET & 0.387 & & 0.856 & & 1.325 & \\
\hline CUSUM & $\mathrm{S}$ & & $\mathrm{S}$ & & $\mathrm{S}$ & \\
\hline CUSUM-sq & $S$ & & $\mathrm{~S}$ & & $\mathrm{~S}$ & \\
\hline
\end{tabular}

\section{Conclusion And Implications}

Global warming and climate change have become the central theme of all international forums and conferences. As a result, researchers and policymakers tried to find the factors that can mitigate carbon emissions, a major cause of rising temperature. Literature has concluded that renewable energy sources could prove a panacea for environment-related problems. Therefore, recently policymakers have shifted their focus in finding the determinants of renewable energy consumption. In this regard, investment in research and development proved to be an important factor in transforming the energy structure of the economy and helping the nation to increase the share of renewable energy in the total energy mix. Consistent with this view, the main objective of this study is to investigate the impact of research and development intensity on renewable energy consumption in Asian economies. We have relied on the autoregressive distributive lag (ARDL) model to get empirical estimates. 
The results show that the short and long-run estimates attached to research and development intensity are significantly positive in China and Japan, signifying that a rise in research and development intensity increases the renewable energy consumption in Asian economies. Conversely, the short-run estimated coefficients of energy intensity are significantly negative in India and positive in Japan. In the long run, the estimates of energy intensity are positive and significant in India and Japan only. The short-run estimates of $\mathrm{CO} 2$ appeared to be significant in India and Japan; whereas, the long-run estimates are significantly positive in all three countries. However, the short-run estimate of trade is significant only in China, and the long-run estimates are significantly positive in China and Japan. Lastly, an increase in financial development increases renewable energy consumption in India and China in the long run but, in the short-run, reduces renewable energy consumption in China only.

Based on the findings, we provide some important policy guidelines. Our findings imply that increased research and development intensity causes renewable energy consumption to rise. Therefore, policymakers should focus on investing more in research and development activities that will improve the process of technological innovations in the economy. The overall technological improvement in the economy has a positive external impact on the energy sector, which increases the renewable energy share in the total energy mix. Given the importance of research and development activities in controlling carbon emissions, the need of the hour is that countries should share their research and development experiences with each other. In this regard, Asian economies should follow the footprint of advanced economies that have attained sustainable development by investing heavily in research and development activities and technological innovations.

\section{Declarations}

Ethical Approval: Not applicable

Consent to Participate: I am free to contact any of the people involved in the research to seek further clarification and information

Consent to Publish: Not applicable

Authors' Contributions: This idea was given by Wei Li. Wei Li and Sana Ullah analyzed the data and wrote the complete paper. While Sana Ullah read and approved the final version.

Funding: Not applicable

Competing Interests: The authors declare that they have no conflict of interest.

Availability of data and materials: The datasets used and/or analyzed during the current study are available from the corresponding author on reasonable request.

\section{References}

1. Bosetti V, Tavoni M (2009) Uncertain R\&D, backstop technology and GHGs stabilization. Energy Econ 31:S18-S26

2. Carfora A, Pansini RV, Romano AA, Scandurra G (2018) Renewable energy development and green public policies complementarities: The case of developed and developing countries. Renewable Energy 115:741-749

3. Castellani D, Pieri F (2013) R\&D offshoring and the productivity growth of European regions. Res Policy 42(9):1581-1594

4. Churchill SA, Inekwe J, Ivanovski K (2021) R\&D expenditure and energy consumption in OECD nations.Energy Economics,105376

5. Dinda S (2004) Environmental Kuznets curve hypothesis: a survey. Ecol Econ 49(4):431-455

6. Fernández YF, López MF, Blanco BO (2018) Innovation for sustainability: the impact of R\&D spending on C02 emissions. J Clean Prod 172:3459-3467

7. Garrone P, Grilli L (2010) Is there a relationship between public expenditures in energy R\&D and carbon emissions per GDP? An empirical investigation. Energy policy 38(10):5600-5613

8. Grimaud A, Lafforgue G, Magné B (2011) Climate change mitigation options and directed technical change: A decentralized equilibrium analysis. Resour Energy Econ 33(4):938-962

9. Jian L, Sohail MT, Ullah S, Majeed MT (2021) Examining the role of non-economic factors in energy consumption and CO2 emissions in China: policy options for the green economy. Environmental Science and Pollution Research,1-10

10. Komen MH, Gerking S, Folmer H (1997) Income and environmental R\&D: empirical evidence from OECD countries. Environ Dev Econ 2(4):505-515

11. Lee KH, Min B (2015) Green R\&D for eco-innovation and its impact on carbon emissions and firm performance. J Clean Prod 108:534-542

12. Li M, Wang Q (2017) Will technology advances alleviate climate change? Dual effects of technology change on aggregate carbon dioxide emissions. Energy Sustain Dev 41:61-68

13. Marangoni G, Tavoni M (2014) The clean energy R\&D strategy for 2 C. Climate Change Economics 5(01):1440003

14. Meleddu M, Pulina M (2018) Public spending on renewable energy in Italian regions. Renewable Energy 115:1086-1098

15. Minniti A, Venturini F (2017) R\&D policy, productivity growth and distance to frontier. Econ Lett 156:92-94

16. Newell S, Robertson M, Scarbrough H, Swan J (2009) Managing knowledge work and innovation. Macmillan International Higher Education

17. Pesaran MH, Shin Y, Smith RJ (2001) Bounds testing approaches to the analysis of level relationships. J Appl Econom 16(3):289-326

18. Ullah S, Ozturk I, Majeed MT, Ahmad W (2021) Do technological innovations have symmetric or asymmetric effects on environmental quality? Evidence from Pakistan. J Clean Prod 316:128239 
19. Usman A, Ozturk I, Ullah S, Hassan A (2021) Does ICT have symmetric or asymmetric effects on CO2 emissions? Evidence from selected Asian economies. Technol Soc 67:101692

20. Wang Q, Li S, Pisarenko Z (2020) Heterogeneous effects of energy efficiency, oil price, environmental pressure, R\&D investment, and policy on renewable energy-evidence from the G20 countries. Energy 209:118322

21. Yao Y, Ivanovski K, Inekwe J, Smyth R (2019) Human capital and energy consumption: Evidence from OECD countries. Energy Econ 84:104534

22. Zhou X, Zhang M, Zhou M, Zhou M (2017) A comparative study on decoupling relationship and influence factors between China's regional economic development and industrial energy-related carbon emissions. J Clean Prod 142:783-800 